\title{
Análise da vulnerabilidade ambiental em áreas protegidas: o caso da APA do Maracanã - São Luís/MA
}

\author{
Marly Silva de Morais ${ }^{(a)}$, Gilberlene Serra Lisboa ${ }^{(b)}$, Jerfesson Domingos Viana ${ }^{(c)}$, José \\ Fernando Rodrigues Bezerra ${ }^{(d)}$
}

(a) Mestranda em Geografia, Dinâmica da Natureza e do Espaço/Universidade Estadual do Maranhão, marlymorais22@hotmail.com

(b) Mestranda em Geografia, Dinâmica da Natureza e do Espaço/Universidade Estadual do Maranhão, gilberlene_serra@yahoo.com.br

(a) Graduado em Geografia Licenciatura e Bacharelado/ Universidade Estadual do Maranhão, jefferson.viana@hotmail.com

(d) Professor do Departamento de História e Geografia/Universidade Estadual do Maranhão, fernangeo@yahoo.com.br

\section{EIXO: BIOGEOGRAFIA, MANEJO DE ÁREAS NATURAIS E PROTEGIDAS: CONSERVAÇÃO DA BIODIVERSIDADE}

\begin{abstract}
Resumo:
As áreas de Proteção Ambiental são instituídas pelo Poder Público. Como unidade de conservação sustentável, a APA permite a ocupação humana. No entanto seu uso desordenado causa a deterioração do ecossistema. Neste sentido, o presente trabalho teve como objetivo analisar e caracterizar a vulnerabilidade ambiental da APA do Maracanã para compreensão dos elementos e fatores que compõem o seu espaço, dinâmica e processos, para tentar minimizar os impactos ambientais negativos. Para alcançar estes objetivos realizou-se um levantamento bibliográfico, trabalhos de campo, além de técnicas de geoprocessamento para caracterizar os componentes geoambientais, considerando o levantamento e o cruzamento desses aspectos, a partir da proposta de Tricart (1977) e Ross (1990, 1991, 1992 e 1994). Como resultado, verificou-se que a área de altíssima vulnerabilidade ambiental ocupa cerca de $4,6 \%$, a forte $28,5 \%$ enquanto a média ocupa $49,2 \%$, a baixa $14,6 \%$ e a muito baixa $3,1 \%$. Pôde-se concluir que a área de estudo constitui um local de média vulnerabilidade ambiental.

Palavras chave: Área de Proteção Ambiental; Vulnerabilidade Ambiental; Impacto Ambiental.
\end{abstract}

\section{Introdução}

A vulnerabilidade é um termo abrangente possuindo variadas intepretações. Diante do senso comum, o Dicionário Aurélio Básico da Língua Portuguesa (1988) explica que algo vulnerável refere-se à fragilidade de um assunto ou questão ou uma situação na qual um indivíduo pode ser atacado ou ferido. No entanto sua compreensão vai além. Vários autores abordam e discutem esse tema assimilando-o com outros conceitos, por exemplo, susceptibilidade, sensibilidade, fragilidade, adjetivando-a com outros termos de acordo com o objetivo de sua pesquisa, como Vulnerabilidade Social ${ }^{1}$, Vulnerabilidade Natural ${ }^{2}$ e, mais

\footnotetext{
${ }^{1}$ É entendida a partir de múltiplos condicionantes. Nesse sentido, "não é uma essência ou algo inerente a algumas pessoas e a alguns grupos, mas diz respeito a determinadas condições e circunstâncias que podem ser minimizadas ou revertidas" (PAULILO, 2000).
} 
especificamente Vulnerabilidade Ambiental. (TURNER et al, 2003a; ADGER, 2006; MARANDOLA e HOGAN 2009; KAWAKUBO et al, 2005 ROSS 1994). Neste trabalho Vulnerabilidade será explanada como Vulnerabilidade Ambiental, visando à relação mútua natureza-sociedade.

A Vulnerabilidade Ambiental está intrinsicamente ligada à ação antrópica. Para Santos (2006), a vulnerabilidade ambiental pode ser entendida como o grau de exposição que determinado ambiente está sujeito a diferentes fatores que podem acarretar efeitos adversos, tais como impactos e riscos, derivados ou não das atividades socioeconômicas. Corroborando com essa temática Tagliani (2012) afirmar que a Vulnerabilidade Ambiental significa maior ou menor susceptibilidade de um ambiente a um impacto potencial provocado por um uso antrópico qualquer.

Os sistemas ambientais representam entidades organizadas na superfície terrestre, de modo que a espacialidade se torna uma das suas características inerentes. A organização desses sistemas vincula-se com a estruturação e funcionamento de (e entre) seus elementos (CHISTOFOLETTI, 1999). Partindo deste pressuposto, o desmatamento e uso inadequado do solo comprometem o habitat natural e a disponibilidade e qualidade dos recursos fornecidos pela natureza.

Nesta conjuntura, é primordial a manutenção de ambientes naturais. Por esta razão foi estabelecido no Brasil o instrumento legal para conservar e proteger a natureza, intitulado Sistema Nacional de Unidades de Conservação - (SNUC), onde esta unidade de conservação - UC, é o elemento fundamental para assegurar a sobrevivência de ecossistemas terrestres e aquáticos.

As Ucs brasileiras de uso sustentável, categoria da APA do Maracanã, são definidas como uma área em geral extensa, com certo grau de ocupação humana, dotada de atributos abióticos, bióticos, estéticos ou culturais especificamente importantes para a qualidade de vida e o bem estar das populações humana, e tem como objetivos básicos proteger a diversidade biológica, disciplinar o processo de ocupação e assegurar a sustentabilidade do uso dos recursos naturais (BRASIL, 2000).

No entanto a expansão urbana tem acontecido de maneira intensa em todo o Brasil desde os anos 1960, e em São Luís (MA) não foi diferente. Segundo a análise realizada por Diniz (2007) apud Silva (2012), o crescimento urbano de São Luís aumentou consideravelmente nas últimas 3 décadas. Especialmente em áreas protegidas por lei, como o caso da APA do Maracanã.

A APA do Maracanã apresenta atualmente um quadro de diminuição dos recursos naturais, ecossistemas destruídos por conta do aumento da construção de conjuntos habitacionais, shopping centers, malhas

\footnotetext{
${ }^{2}$ A vulnerabilidade natural ou fragilidade ambiental definida a partir das Unidades Ecodinâmicas (TRICART, 1977), apresentam características particulares dos componentes que os constituem (relevo, as rocha, o clima e os solos), e que os classificam como frágeis (ROSS, 1994).
} 
hidroviárias entre outros, além de acarretar na devastação da cobertura vegetal têm intensificado os processos erosivos acelerados e o assoreamento dos rios.

Partindo deste panorama atual na APA do Maracanã, analisar e caracterizar a vulnerabilidade ambiental desse ambiente é peça chave na elaboração do Plano de Manejo, pois permite diagnosticar a situação apontando soluções que minimizem os impactos ambientais.

Neste sentido, o presente trabalho teve como objetivo analisar e caracterizar a Vulnerabilidade Ambiental da APA do Maracanã, através de técnicas de geoprocessamento e trabalhos de campo, como subsídio de planejamento e gestão ambiental.

\section{Materiais e Metódos}

Este estudo está fundamentado em pesquisas bibliográficas, trabalhos de campo e interpretação de produtos de sensoriamento remoto para o mapeamento. Os trabalhos de campo tiveram como objetivo a observação in loco da influência da ação antrópica.

Para o mapeamento, processamento e espacialização dos dados referentes à Vulnerabilidade Ambiental na APA do Maracnã, utilizou-se o software ArcGIS for Desktop Advanced, versão 10.2, licença EFL999703439.

$\mathrm{Na}$ elaboração do mapa de localização da área na bacia hidrográfica do Bacanga foram utilizadas cartas topográficas da DSG/ME- MINTER, (que estão disponibilizadas na página do ZEE-MA, Zoneamento Ecológico-Econômico do Estado do Maranhão), folhas 13, 21, 22, 23, 29, 30, 31, 38 e 39, referentes à área de estudo, na escala de 1:10.000. Adquiriu-se o banco de dados de Bezerra (2011) e Silva (2012), nos quais havia shapes referentes aos aspectos geoambientais da área, incluindo a vetorização da drenagem e das curvas de nível. A partir dos trabalhos de campo com auxilio do GPS marcou-se os polígonos e pontos referentes aos processos identificados na área, uma vez que o mapa proposto é de localização com os processos antrópicos da bacia hidrografia do Bacanga.

No decorrer da pesquisa mapearam-se áreas com processos erosivos acelerados, áreas de extração mineral ilegal e construçoes habitacionais, que se baseando no princípio das Unidades Ecodinâmicas preconizadas por Tricart (1977) e a proposta metodológica de Ross (1990, 1992, 1994), através do levantamento básico de geomorfologia (declividade e grau de dissecação do relevo), solos (erodibilidade dos solos), cobertura vegetal / uso da terra e clima (índices pluviométricos) ressultaou no mapa de Vulnerabilidade Ambiental. O detalhamento é exposto em uma escala de 1 a 5, expressa pelos códigos: muito fraca (1), fraca (2), média (3), forte (4) e muito forte (5). 


\section{Resultados e Discussões}

A APA do Maracanã foi criada pelo Decreto de Estadual n 12.103 de 01 de outubro de 1991 com uma área de 1.831 ha. Limita-se ao norte com o Rio Maracanã (limite sul do PEB), ao leste pela BR - 135, a oeste pelo Módulo 9 do Distrito Industrial e ao Sul pela localidade Rio Grande (Figura 1).

A área de estudo encontra-se inserida na Província Estrutural Parnaíba (Bacia do Grajaú) e Província Estrutural Costeira (IBGE 2011). Suas estruturas geológicas superficiais são constituídas por rochas da Formação Itapecuru, Barreiras ${ }^{3}$ e Açuí. Possui um relevo com feições típicas das litologias dominantes em bacias sedimentares submetidas a longos períodos de atividades dos agentes externos, originando as formas tabulares e subtabulares das superfícies erosivas intercaladas por colinas dissecadas e esparsas, bem como as formas deposicionais como planície de maré e planície fluvial.

\subsection{Uso e Ocupação do solo}

As interações entre a sociedade e natureza, na APA do Maracanã ${ }_{2}$ deveriam ocorrer de forma sustentável, entretanto o processo de ocupação desordenada está causando uma seria de impactos ambientais, como poluição dos rios, desmatamento, processos erosivos acelerados e assoreamento dos canais fluviais (FILHO, 2010). Segundo Mota (1997) as áreas desmatadas são as mais sujeitas à ação desagregadora da água e do vento, pois a vegetação tem o efeito de restringir o impacto da chuva sobre o solo, servindo como barreira física para o transporte de materiais.

\footnotetext{
3 O termo "Barreiras" tem sido utilizado pela literatura geológica ora como "Formação", ora como "Grupo" e dantes, como "Série", a qual foi considerada imprópria, por representar unidades cronoestratigráficas, não coerente para o caso, pois se desconhecem os limites de sua sedimentação no tempo geológico. A designação Formação Barreiras, segundo Bigarella et al. (2007), também não parece adequada devido à presença de inconformidades erosivas e grande variação litológica. Devido às dificuldades de se classificar a sequência Barreiras, Matoso e Robertson (1959) utilizam a expressão formações cenozóicas indiferenciadas ou indivisas, contudo Bigarella e Andrade (1964) desenvolveram pioneiramente uma proposta de subdivisão do Barreiras, passando a usar a denominação Grupo.
} 


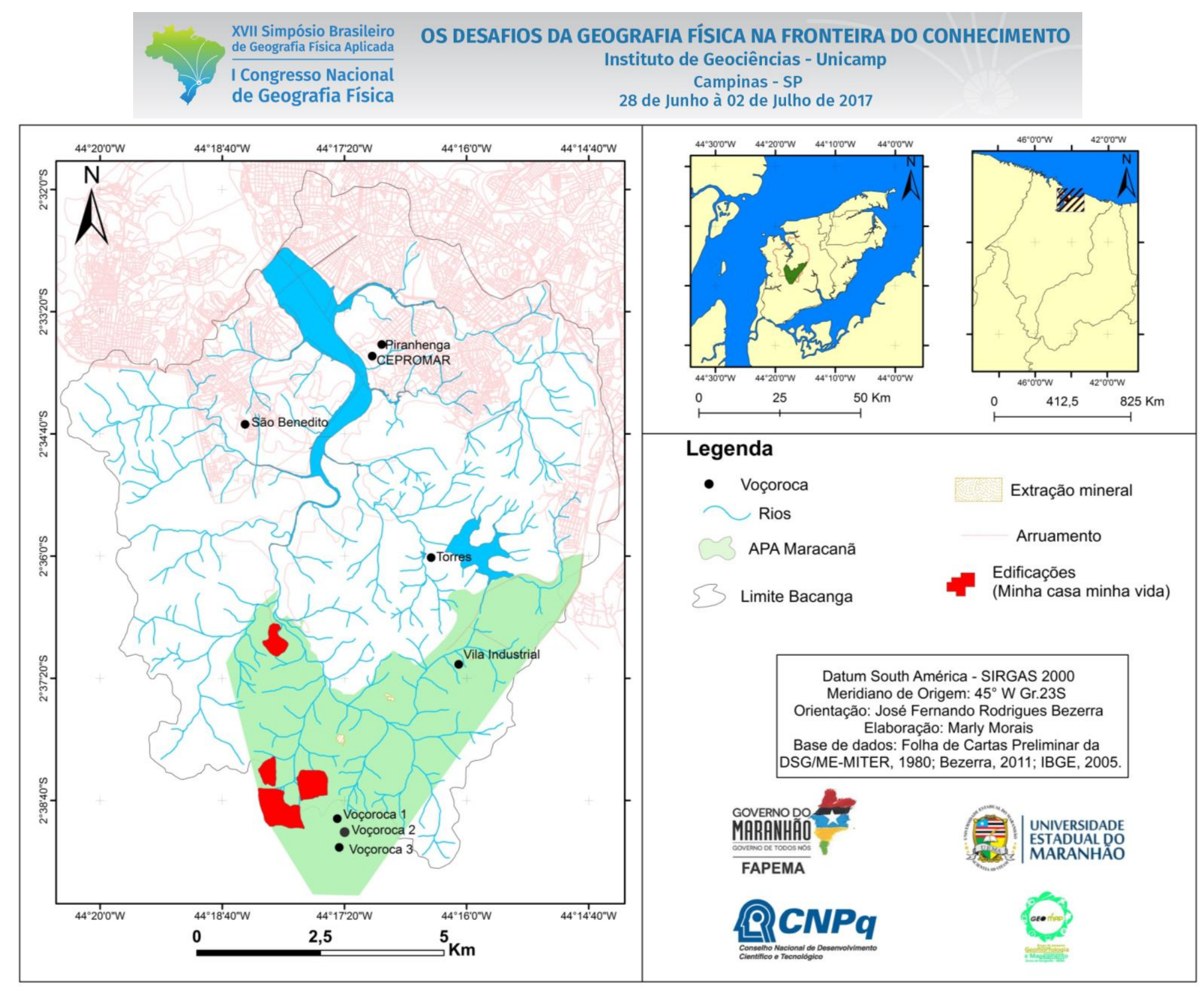

Figura 1: Localização da APA do Maracanã com ocorrência de processos erosivos, área de extração mineral e construções de conjuntos habitacionais, São Luís, MA. 
$\mathrm{Na}$ área de estudo, a partir da classificação supervisionada e de acordo com os objetivos desde trabalho, foram identificados três (3) categorias de uso e ocupação, sendo elas: Área Construída, Floresta Secundária Mista e Solo Exposto (Tabela 1).

Tabela 1: Categorias de uso e ocupação do solo da APA do Maracanã ano de 2016

\begin{tabular}{l|c|c}
\hline \multirow{2}{*}{ Categorias } & \multicolumn{2}{c}{ Área } \\
\cline { 2 - 3 } & Valor absoluto $\left(\mathbf{K m}^{\mathbf{2}}\right)$ & Valor relativo (\%) \\
\hline Água & 0,03 & 0,16 \\
\hline Área construída & 8,77 & 47,87 \\
\hline Floresta secundária mista & 6,88 & 37,57 \\
\hline Solo exposto & 2,63 & 14,36 \\
\hline \multicolumn{1}{c|}{ Total } & $\mathbf{1 8 , 3 1}$ & $\mathbf{9 9 , 9 6}$ \\
\hline
\end{tabular}

De acordo com o mapeamento realizado o mau uso do solo, representado pelos processos erosivos acelerados, área de extração mineral e edificações estão inseridos respectivamente na categoria área construída (classe 2) e solo exposto (classe 5). A categoria de uso área construída possui a maior área, com $8,77 \mathrm{~km}^{2}$ representando 47,87\% do total (área construída englobando os mais diversos tipos de construção, inclusive as áreas de ocupação).

A floresta secundária mista representa a cobertura vegetal oriunda "da devastação da floresta, por processos que vão desde o arrasamento da área (...) até a retirada das árvores com valor econômico"(...). Adiciona-se a "ocorrência da vegetação secundária latifoliada (...) e as palmeiras" (MARANHÃO, 1998, p. 84). Pode ser subdividida em: (mata secundária de terra firme, capoeira e palmácias/babaçuais). Na área de estudo abrange $6,88 \mathrm{~km}^{2}$ o que implica a $37,57 \%$ sendo grande parte no limite do Parque Estadual do Bacanga.

A APA atualmente apresenta $2,63 \mathrm{~km}^{2}$ de solo exposto, este valor representa $14,36 \%$ da área total, encontrada nas proximidades de áreas urbanizadas onde acontecem a extração de areia, silte, argila e laterita para construção civil.

Segundo Filho et al (2010), a extração mineral (Figura 2) é desenvolvida há muito tempo dentro da área de estudo, antes mesmo de esta se transformar em Área de Proteção Ambiental. Essa prática acontecia de forma muito rústica, sem o uso de máquinas, sendo que as jazidas lateríticas eram descobertas por acaso. Quando agricultores abriam áreas para plantio, por vezes achavam afloramento das rochas, que eram retiradas para o uso próprio ou comercializadas em pequena escala na mesma localidade. 


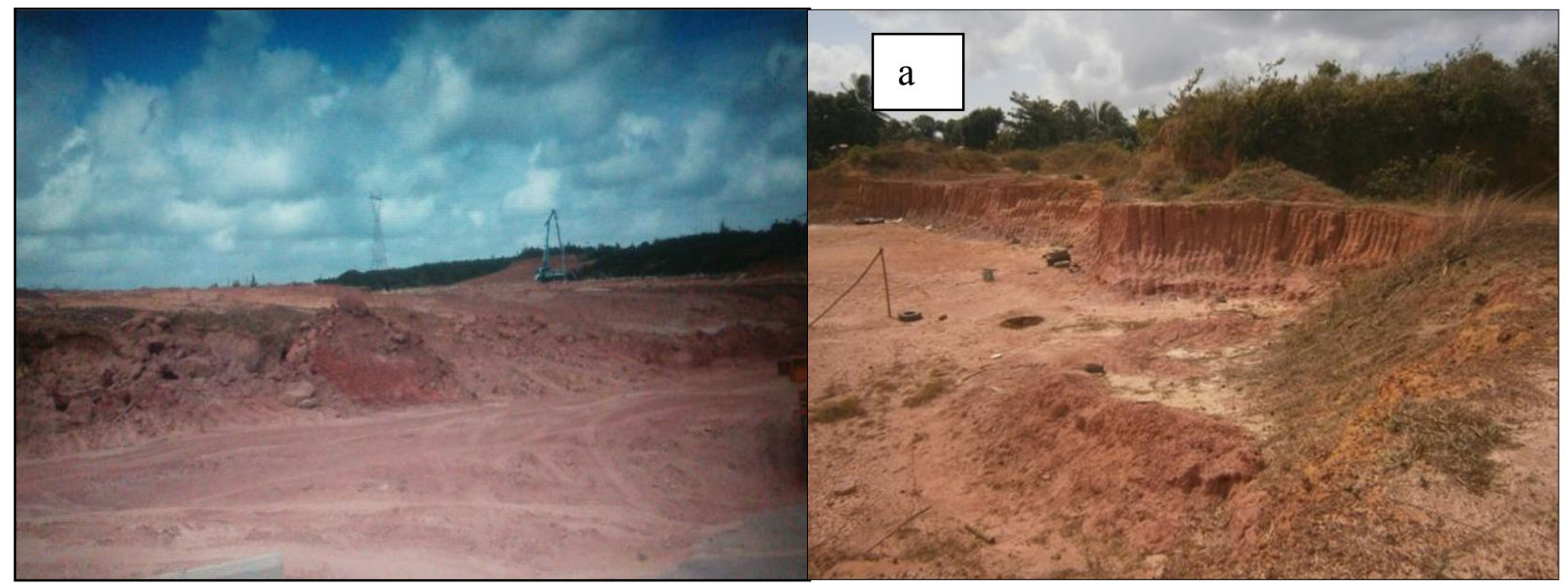

Figura 2: Área de extração sedimentar nas proximidades das edificações (a) e a voçoroca da Vila Industrial (b) que também apresenta áreas de extração na APA do Maracanã, 2016.

No entanto o aumento da demanda e valorização do produto nos depósitos de material de construção civil em São Luís tornou-se um verdadeiro empreendimento econômico envolvendo empresários, maquinário (caçambas e tratores) grandes áreas de extração e mão-de-obra barata.

Tal atividade deveria apresentar Licenciamento Ambiental, segundo a Resolução CONAMA nº 001/1986, no seu Art. $2^{\circ}$ capítulo IX. Ressalta-se que o Licenciamento não seria autorizado, pois segundo a Resolução CONAMA n” 10/1988 Art. 6 define que "Não serão permitidas nas APA's as atividades de terraplanagem, mineração, dragagem e escavação que venham causar danos ou degradação do meio ambiente e /ou perigo para pessoas ou biota".

Em conversas com moradores da APA, as extrações são constantemente fechadas, no entanto as empresas que hoje dominam o mercado dentro da UC, sempre voltam a pratica-la. Ainda sobre o relato do morador a mata que correspondia às palmáceas já foi completamente degradada, causando o assoreamento do Rio Ambude.

Confirma-se então que a atividade de extração sedimentar ocorre de forma irregular, por conta do mau gerenciamento desta UC. É necessária uma intervenção imediata antes que os danos tornem-se irreversíveis. Como o solo exposto é desprovido de cobertura vegetal, ocasiona a intensificação da erosão pluvial. $\mathrm{Na}$ área de estudo essa influência de uso aponta vários impactos ambientais negativos, entre eles a redução de nutrientes do solo, assoreamento de rios (Figura 3) e o avanço dos processos erosivos acelerados, pois a água da chuva promove a desagregação e o transporte de sedimentos. 


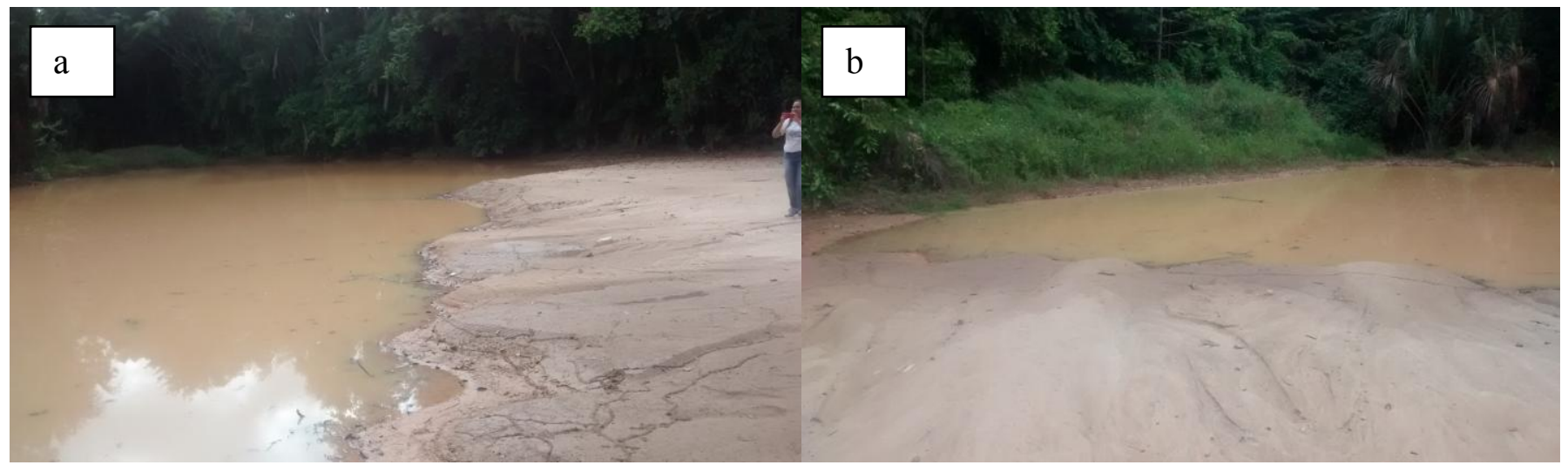

Figura 3: As fotos a e b demonstram o assoreamento do Rio Ambude localizado na APA do Maracanã, por conta da extração mineral e desmatamento para construções de residências, 2016.

Neste sentido Oliveira (2011) destaca que a degradação da qualidade ambiental em decorrência de condutas e atividades lesivas ao meio ambiente natural remanescente e cultural (construído) torna-se cada vez mais presente e visível no cotidiano da Área de Proteção Ambiental (APA) do Maracanã, exposta a toda sorte de impactos e agressões, advindos principalmente da intensa concentração populacional do entorno e do contínuo processo de urbanização e industrialização.

A APA do Maracanã não possui Plano de Manejo, facilitando ainda mais as atividades predatórias que causam os problemas já citados anteriormente. É necessário que sejam adotadas inicialmente medidas mitigadoras para que no futuro esses problemas possam ser solucionados.

\subsection{Vulnerabilidade Ambiental}

O cruzamento das informações, referentes à pedologia, geomorfologia, geologia, índices pluviométricos, uso e ocupação do solo e com base na experiência na área de estudo, resultaram no mapa de vulnerabilidade ambiental da APA do Maracanã, na qual foi possível identificar as vulnerabilidades muito baixa ou nula, baixa, média, forte e muito forte (Figura 4).

A aceleração dos processos morfogenéticos na área em estudo está relacionada à expansão urbana e industrial, sem planejamento e com caráter especulativo, pois a pequena amplitude altimétrica e a baixa declividade das unidades geomorfológicas não oferecem limitações para o uso e ocupação do solo, ocasionando o surgimento de vários problemas ambientais, dentre eles, o surgimento e evolução de processos erosivos acelerados e consequentemente o assoreamento e poluição dos rios. Foram identificadas quatro feições erosivas aceleradas denominadas de Vila Industrial, Voçorocas 1,2 e 3 que estão relacionadas às vulnerabilidades muito forte, baixa e forte (Figura 4). 


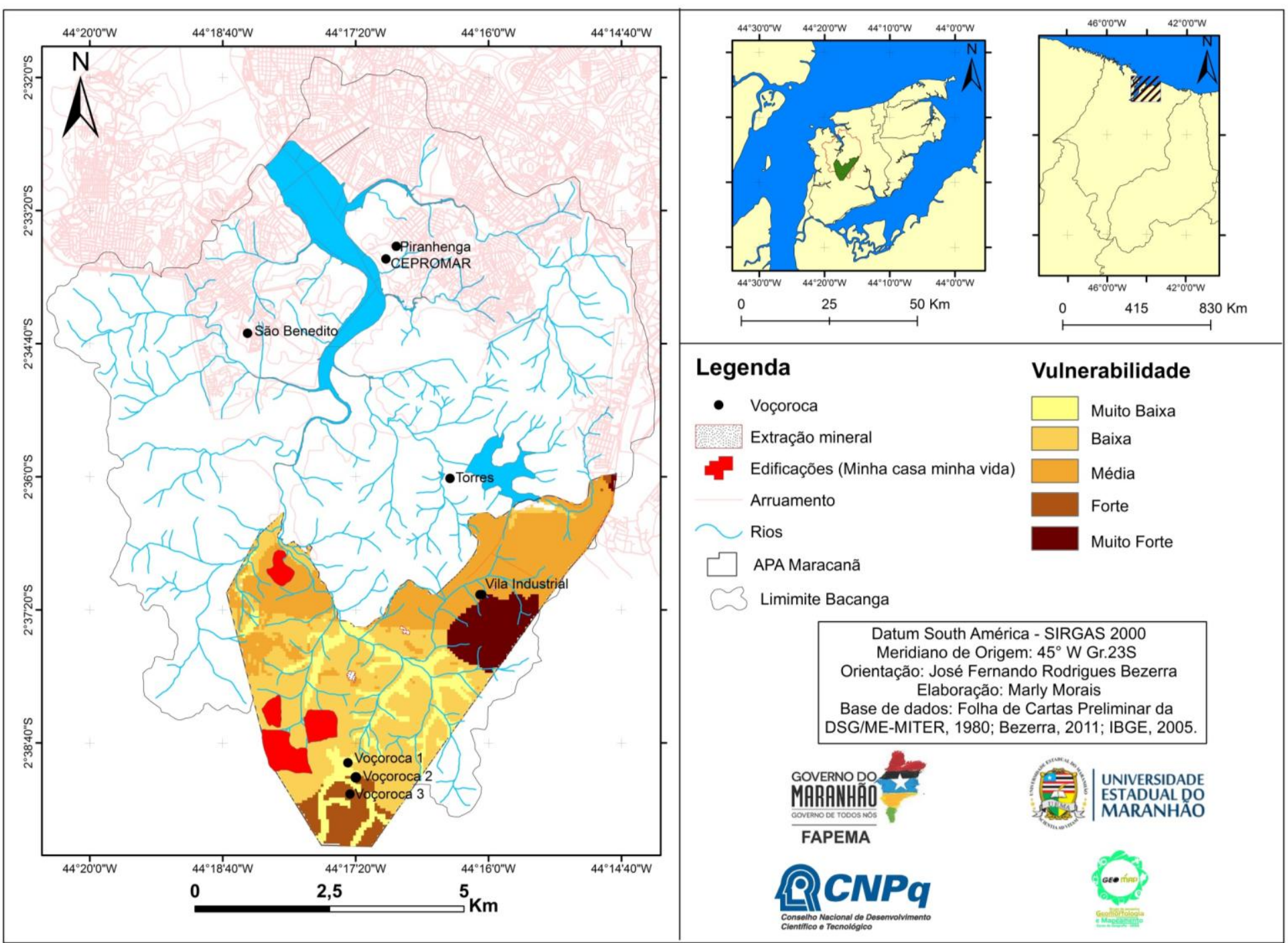

Figura 4: Mapa de Vulnerabilidade Ambiental da APA do Maracanã, São Luís-MA. 
Conforme observado na (figura 4), a vulnerabilidade média representa 49,2\% da área total, seguida das vulnerabilidades forte $(28,5 \%)$ e Baixa $(14,6 \%)$. As áreas de menores representatividades espaciais na área de estudo, são as vulnerabilidades muito forte e muito baixa ou nula, que chegaram a 4,6\% e 3,1\% respectivamente.

Todos esses processos de voçorocamentos e assoreamento dos rios iniciam-se com o inadequado manejo do solo, que resulta na retirada da cobertura vegetal original, deixando o solo exposto a ação dos agentes intempéricos, principalmente as chuvas concentradas nos meses de janeiro a junho. Os solos são altamente friáveis e mal consolidados, não oferecem nenhuma resistência à ação das gotas de chuvas, que selam a superfície do solo, composta principalmente, pela fração franco-siltosa (BEZERRA, 2011), tendendo a formação de encrostamento e diminuição da taxa de infiltração e rápida formação do escoamento superficial.

\section{Conclusões}

A metodologia aplicada mostrou-se adequada aos objetivos propostos, pois através da conexão de alguns fatores do meio físico mais o uso e ocupação, foi possível obter uma visão geral da vulnerabilidade ambiental da APA do Maracanã.

Foram encontrados processos erosivos acelerados e lineares, como as voçorocas e ravinas, que colocam em risco a estabilidade do terreno e compromete a disponibilidade das águas provocando o transporte de sedimentos acarretando mudanças na infiltração e escoamento superficial.

A vulnerabilidade ambiental da APA foi classificada entre muito baixa e muito forte, demonstrando os desequilíbrios que se processam na UC, os resultados são favoráveis para a compreensão do grau de influência dos componentes naturais e antrópicos auxiliando no planejamento ambiental.

Os resultados alcançados são de grande importância para o zoneamento da APA do Maracanã, por ser uma reavaliação, servindo de subsídio para gestão territorial de maneira planejada e sustentável, evitando problemas de ocupação desordenada principalmente em áreas já protegidas por lei.

É necessário atentar, principalmente ao comprometimento dos recursos hídricos, uma vez que estes possuem múltiplos usos na região e tem sido impactado ao longo dos anos. Portanto é necessário o respeito às normas ambientais voltadas à utilização desses recursos, bem como, o gerenciamento do espaço geográfico em busca do menor impacto possível. 


\section{Bibliografia}

ADGER W. Vulnerability. Tyndall Centre for Climate Change Research, School of Environmental Sciences. University of East Anglia, Norwich NR4 7TJ, UK. 2006. p.1-14

BRASIL. Lei $\mathrm{n}^{\circ} 9.985$ de 18 de julho de 2000. Regulamenta o art. 225, $\mathbf{1}^{\mathbf{0}}$, incisos I, II, III e VII da Constituição Federal, institui o Sistema Nacional de Unidades de Conservação (SNUC) e dá outras providências. Diário Oficial da União, 2000.

BEZERRA, J. F. R. Geomorfologia e reabilitação de áreas degradadas por erosão com técnicas de bioengenharia de solos na bacia do rio Bacanga, São Luís, Maranhão. Tese de Doutorado. Rio de Janeiro Universidade Federal do Rio de Janeiro, 2011.

CATELLANI, Rodrigo. Utilização de Técnicas em Sistemas de Informações Geográficas para a determinação da Vulnerabilidade Natural e Ambiental da região do Campo Petrolífero do Canto do Amaro na Bacia Potiguar/RN. 2004. 114f. Dissertação (Mestrado) - Curso de Geociências, UFRN, Natal, 2004.

CHISTOFOLETTI, A. Modelagem de sistemas ambientais. São Paulo: Edgard Blücher, 1999. 236 p.

CONAMA. Conselho Nacional do Meio Ambiente. Resolução CONAMA nº 10, de 01 de janeiro de 1986. Avaliação de Impacto Ambiental. Disponível em: 〈www.mma.gov.br〉. Acesso em: 18 de junho de 2015.

CONAMA. Conselho Nacional do Meio Ambiente. Resolução CONAMA nº 10, de 14 de dezembro de 1988. Área de Proteção Ambiental e Zonas de Conservação. Disponível em: <www.mma.gov.br〉. Acesso em: 18 de junho de 2015.

FARIAS FILHO, Marcelino Silva. Caracterização geoambiental da Área de Proteção Ambiental da Região do Maracanã, São Luís -MA. In__ CARVALHO NETA, R. N. F (org). Área de Proteção Ambiental do Maracanã: subsídios ao manejo e à Educação Ambiental. São Luís: FAPEMA, Café \& Lápis, 2010. 15 -39 p.

FERREIRA, Aurélio Buarque de Holanda. Dicionário Aurélio Básico da Língua Portuguesa. Rio de Janeiro: Nova Fronteira, 1988, p. 214

IBGE. Instituto Brasileiro de Geografia e Estatística. Mapa das províncias estruturais e domínios geotectônicos. In: http://geoftp.ibge.gov.br/mapas/tematicos/tematico_estadual/- Rio de Janeiro. 2011. Acesso em 25/07/2013.

KAWAKUBO, F. S.; MORATO, R. G.; CAMPOS, K. C.; LUCHIARI, A.; ROSS, J. L. S. 2005. Caracterização empírica da fragilidade ambiental utilizando geoprocessamento. In:Anais XII Simpósio Brasileiro de Sensoriamento Remoto, Goiânia, INPE, p. 2203-2210.

MARANDOLA, E. \& HOGAN, D. Vulnerabilidade do lugar vs. Vulnerabilidade sociodemográfica: implicações metodológicas de uma velha questão. Revista Brasileira de Estudos Populacionais, Rio de Janeiro, v. 26, n. 2, p.161-181, jul. 2009.

MARANHÂO. Instituto Brasileiro de Meio Ambiente e Recursos Naturais do Estado do Maranhão. Secretaria de Estado do Meio Ambiente e Recursos Hídricos. Diagnóstico ambiental da microrregião da aglomeração urbana de São Luís e dos Municípios de Alcântara, Bacabeira e Rosário. São Luís, 1998.

MOTA, S. Introdução a Engenharia Ambiental. Rio de Janeiro: ABES, 1997. 292p.

OLIVEIRA, M. S. Mudanças no uso e ocupação do solo decorrentes da industrialização e suas implicações socioambientais na APA do Maracanã e zona de amortecimento. Projeto de monografia. São Luís: UFMA, 2011.

SANTOS, J.O. do. Vulnerabilidade Ambiental e Áreas de Risco na Bacia Hidrográfica do Rio Cocó - RMF, (Dissertação de Mestrado) UECE, 2006. p.212.

ROSS J. L.S. Geomorfologia ambiente e planejamento. Contexto. São Paulo, 1990.

O registro cartográfico dos fatos geomorfológicos e a questão da taxonomia do relevo. Revista do

Departamento de Geografia, n.6, São Paulo: Edusp, p. 17-30. 1992. 


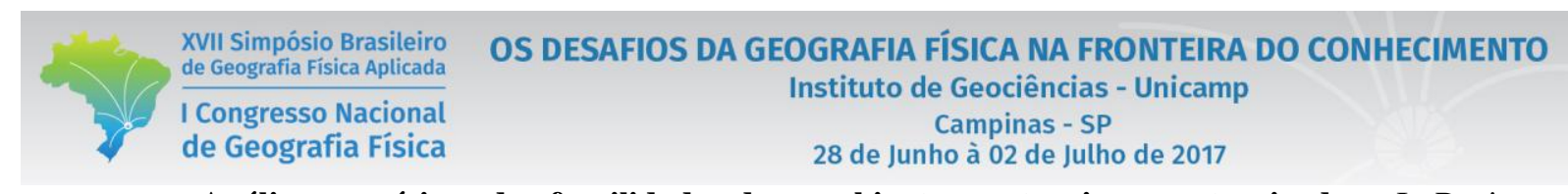

Departament Análise empírica da fragilidade dos ambientes naturais e antropizados. In:Revista do

SILVA, Q. D. Mapeamento geomorfológico da Ilha do Maranhão/ Tese de Doutorado. Presidente PrudenteUniversidade Estadual de São Paulo, 2012.

TAGLIANI C.R.A. Técnica para avaliação da vulnerabilidade de ambientes costeiros utilizando um Sistema Geográfico de Informações. Porto Alegre, UFRGS. 2002. Disponível em: <http://www.fatorgis.com.br>. Acesso em: 09 abril. 2017.

TURNER II, B.; KASPERSON, R.; MATSON, P.; MCCARTHY, J.; CORELL, R.; CHRISTENSEN, L.; ECKLEY, N.; KASPERSON, J.; LUERS, A.; MARTELlO, M.; POLSKY, C.; PULSIPHER, A.; SCHILLER, A. A Framework for Vulnerability Analysis in Sustainability Science. Proceedings of the National Academy of

Sciences US (PNAS), Vol.100. 2003a. p. 8074-8079.

TRICART, J. Ecodinâmica. Rio de Janeiro: IBGE, 1977. 